\title{
Los maestros alarifes del convento de Santa Inés de Sevilla durante el siglo XVII
}

The alarifes masters of the convent of Santa Inés de Sevilla during the 17th century

\section{Estefanía Medina Muñoz}

Doctora Cum Laude en Historia del Arte por la Universidad de Sevilla, España (estefymedmun1212@gmail.com)

Recibido el 06 de diciembre de 2017; revisado el 10 de enero de 2018; aceptado el 18 de febrero de 2018 ; publicado el 21 de marzo de 2018

RESUMEN: La historia constructiva de un edificio se complementa con las constantes obras de reforma y mantenimiento que en él se realizan. Estas intervenciones menores, de las que fueron testigos las clausuras hispalenses, aportan datos inéditos relativos a la labor de los maestros de obras que trabajaron al servicio de estas instituciones religiosas. El presente artículo propone, como objetivo principal, la difusión del elenco de maestros alarifes que trabajaron, efectuando obras de carácter menor, al servicio de la comunidad de hermanas franciscanas clarisas del sevillano convento de Santa Inés durante el siglo XVII.

PALABRAS CLAVE: Maestros alarifes, obras menores, historia del arte, convento de Santa Inés.

\begin{abstract}
The constructive history of the building is complemented by the constant renovation and maintenance works carried out there. These minor interventions, of which the closures of Seville was witness, provide unpublished data related to the work of the master builders who worked at the service of these religious institutions. The present article is presented as the main objective of the dissemination of the list of alarifes masters who work in the performance of minor functions, at the service of the community of Franciscan Clarisse sisters of the sevillian convent of Santa Inés during the 16th century.
\end{abstract}

KEYWORDS: Masters alarifes, minor works, history of art, convent of Santa Inés 


\section{Introducción}

Según el diccionario de la Real Academia Española de la lengua, el término alarife procede del árabe hispánico al'aríf, y del árabe clásico 'arīfl', "Experto o sabio" (BOSARTE, 1854: 53), vocablo relacionado con la voz arafa, de la que deriva el término arif "reconocedor", al que se añadió el artículo $A l$, dando lugar a la formación de la palabra alarife (Toajas Roger, 1986: 164). La relación del alarife como maestro de obras se remonta a la historiografía del arte mudéjar, documentándose su actividad más temprana en Sevilla en el año de 1287 (Ballesteros Beretta, 1913: 324). Su reglamentación quedó recogida en el Libro del Peso de los alarifes y Balanza de Menestrales (Cómez Ramos, 2006: 161), donde se define a estos artífices como maestros del arte de la construcción, aunque su polifacética figura los encasilló en el siglo XV como maestros de obras, jueces de obras de albañilería y expertos en las artes mecánicas, como bien se mantuvo en la centuria del XVII (Gómez López, 1941: 41).

\section{Juan Bernardo de Velasco como maestro de obras de Santa Inés}

La presencia en Santa Inés de quien fue maestro mayor de obras de los Reales Alcázares y Atarazanas de Sevilla (Marín Fidalgo, 1990: 591), hemos podido documentarla entre los años de 1632 a 1638. Entre sus obras más tempranas destaca su labor en el claustro del convento del Socorro, donde trabajó con el maestro albañil y carpintero Félix Romero (Sancho Corbacho, 1930: 528), bajo las directrices del arquitecto Diego López Bueno (Sancho Corbacho, 1928, 278/ Arenilla Torrejón 1992: 3869), y su colaboración en la decoración de la iglesia del colegio de San Buenaventura junto con Francisco Herrera “el viejo” (González De León, 1844: 30-31). También fue tasador de obras con Cristóbal Ortiz y Marcos de Soto en el convento de la Purísima Concepción de San Juan de la Palma (Cruz Isidoro, 1995: 422), supervisando, junto con este último y los alcaldes alarifes Pedro de Torres, Félix Romero y Bartolomé Vázquez, y los artífices Melchor de la Vega, Juan de Segarra, Diego López de Arenas, Alonso Duran y Jerónimo de Vera, el hundimiento de un muro del refectorio del colegio de San Hermenegildo en 1632 (Marín Fidalgo, 2009: 303). En 1637 (De La Banda Vargas, 2007: 75), consta como visitador de obras del Hospital de las Cinco Llagas junto con Juan de Segarra y Francisco Rodríguez.

En Santa Inés, se encargó de la supervisión de obras en propiedades urbanas, trabajo que vino realizando desde 1632 con el aprecio de unas casas en la collación de Ómnium Sanctorum² ${ }^{2}$ Un año más tarde, recibió 5.864 maravedíes $^{3}$ por unas obras efectuadas en el interior de la clausura. Quizás más interesante sea su posible participación en la reforma barroca de la iglesia, emprendida por Francisco Herrera "el viejo, donde pudo participar en el diseño de sus yeserías. En las cuentas

\footnotetext{
${ }^{1}$ http://dle.rae.es//. (Consulta 10/11/2017)

${ }^{2}$ A.H.P.S: Sección Protocolos Notariales. Oficio 11, Legajo. 6969. Año de 1634. Escribano público Rodrigo de Abreu. Fol. 842.

${ }^{3}$ A.H.P.S: Sección Protocolos Notariales .Oficio 11, Leg. 6966. Año 1633. Escribano Rodrigo de Abreu. Fol. 1220.
} 
de mayordomía de $1633^{4}$, no se especifica la intervención de Herrera "el viejo” en el diseño o ejecución de éstas, aunque su participación es más que evidente. Recordemos que el pintor había diseñado el programa ornamental del Colegio de San Buenaventura, labor que llevaría a la práctica Juan Bernardo de Velasco junto con Juan de Segarra.

La colaboración del alarife en dicha institución nos hace plantear la hipótesis de su posible intervención en la ornamentación del templo de Santa Inés, donde disfrutó del cargo de maestro de obras. Desde el siglo XVI la labor de yeserías era un trabajo adjudicado al maestro albañil, como queda reflejado en las ordenanzas de Sevilla decretadas por los Reyes Católicos (Guerrero Lovillo, 1995: 53). Esta labor yesera emprendida por los maestros de obras siguió viva durante los siglos XVII y XVIII, pudiendo ser éstos los autores del diseño exhortativo a ejecutar, aunque siempre se solía contar con la ayuda de un artista, especialmente cuando el programa ornamental era iconográfico (Quiles García, 1990: 567). Posiblemente, sea así como ocurre en Santa Inés, donde Francisco de Herrera pudo diseñar las yeserías del templo y Juan Bernardo de Velasco el encargado de su ejecución.

Su actividad fue muy prolifera en la clausura durante el año de $1634^{5}$, trabajando en la solería de la puerta de la iglesia, la sepultura de Doña Mencia de Heredia, el empedrado de uno de los compas, el capítulo y los andenes del jardín. No volvemos a tener noticias sobre su quehacer hasta $1637^{6}$, cuando se le pagaron 392 maravedíes por la nueva canal maestra del patio de la Camarilla y la colocación de dos retablos de la iglesia, en los que intervino el maestro carpintero Manuel de Campos.

\section{Diego Martín de Orejuela y la construcción del cuerpo superior de la sacristía exterior}

En $1638^{7}$ se edificó un segundo cuerpo sobre la fábrica renacentista de la sacristía exterior bajo la dirección de Diego Martín de Orejuela, intervención por la que recibió 638 reales en 1639, única actividad documentada del artista en la clausura. Debido al excesivo peso que recaía sobre el

\footnotetext{
${ }^{4}$ A.H.P.S: Sección Protocolos Notariales. Oficio 11, Leg 6966. Año 1633. Escribano público Rodrigo de Abreu. Fol. 104.

${ }^{5}$ A.H.P.S: Sección Protocolos Notariales. Oficio 11, Leg. 6971. Año de 1634. Escribano público Rodrigo de Abreu. Fol.115.

${ }^{6}$ A.H.P.S: Sección Protocolos Notariales. Oficio 11, Leg. 6979. Año de 1637. Escribano público Rodrigo de Abreu. Fol. 829.

${ }^{7}$ A.H.P.S: Sección Protocolos Notariales. Oficio 11, Leg. 6985. Año de 1639. Escribano público Rodrigo de Abreu.Fol.776.
} 
artesonado de esta dependencia, dicha planta fue suprimida con la intervención efectuada en el patrimonio arquitectónico del monasterio por el arquitecto Alberto Humanes Bustamante, quien reconstruyó una nueva cubierta basada en los volúmenes originales (AA.VV, 1990: 172-173). Dicha estancia, estuvo cubierta por una techumbre de madera ejecutada por el carpintero Manuel de Campos, en la que se invirtieron 584 reales $^{8}$ en madera y entregaron 322 reales al citado maestro.

Respecto a Martín de Orejuela, sabemos que ocupó el cargo de maestro mayor de los Alcázares y Atarazanas de Sevilla (Marín Fidalgo 1990: 595). Fue el encargado del diseño del Cenador del León, (Marín Fidalgo 1991: 213-218/ Marín Fidalgo, 2006: 184), de la supervisión de obras del castillo de San Jorge (González De Caldas, 2008: 64,72, 88), entre 1626 y 1638, (González de Caldas, 2000: 285-286), y la tasación de unas pinturas de Juan de Medina, en 1643, en el Alcázar (Gestoso Pérez 2001:397/ Valdivieso González \& Serrera Contreras 1985: 235).

Trabajó también en algunas localidades sevillanas, como en Osuna, en el convento de las concepcionistas en 1576, con la ejecución de la celda de Doña Luisa de Valderrama (Ledesma Gámez \& Martín Vázquez, 2012: 65), y el en desaparecido monasterio de San Francisco en 1586 (Ledesma Gámez, 1996: 117), participando en la terminación de su torre, los dormitorios y la enfermería alta. En 1602, fue convocado para la adjudicación de las obras de la cabecera de la iglesia de San Miguel de Morón de la Frontera, cuyo encargo recayó en el artífice Lorenzo de Oviedo (Morón De Castro, 1995:131).

Respecto a su estancia en Santa Inés, de la cual sospechamos pudo ser similar a su puesto en el Alcázar, entre los años de 1638 y 1649 (Gestoso Pérez, 1889: 471), no tenemos constancia documental que nos permita datar exactamente la fecha de su nombramiento como maestro de obras, coincidiendo su presencia con el año del fallecimiento de Juan Bernardo de Velasco, al que pudo sustituir como ocurrió en los Reales Alcázares.

\section{Las reformas emprendidas por el maestro albañil Fernando de Castro}

Gracias al tributo otorgado por Cristóbal Contreras en $1643^{9}$, se reformaron las cubiertas del dormitorio alto, con un coste de 3.500 reales, de los cuales se destinaron 3.083 reales al pago de materiales, maestros, peones y oficiales. La reforma vino acompañada de una obra de carpintería en

\footnotetext{
${ }^{8}$ A.H.P.S: Sección Protocolos Notariales. Oficio 11, Leg. 6987. Año de 1640. Escribano público Rodrigo de Abreu. Fol. 959.

${ }^{9}$ A.H.P.S: Sección Protocolos Notariales. Oficio 11, Leg. 6993. Año de 1643. Escribano público Rodrigo de Abreu. Fols. 689 y 695.
} 
la que se invirtió 661 reales y medio. Según Arenillas Torrejón (Arenillas Torrejón, 2005: 197), en ese año, Antonio de Fuentes, maestro albañil y alcalde alarife del ayuntamiento hispalense, junto con el maestro carpintero Juan Antonio Escudero y el albañil Fernando de Castro, verificaron el estado del edificio.

El resultado fue la realización de una memoria en la que se detallaron todas las reformas a las que debía ser sometido el monasterio, especialmente sus tejados, que debían realizarse de nuevo en su totalidad. Los trabajos fueron tasados en 7.500 ducados y estarían centrados en los claustros, los dormitorios, el refectorio, las enfermerías, la cocina, la casa de leña, la iglesia y otras estancias de la clausura.

En las cuentas de $1644^{10}$, se recogen diversas tareas realizadas por Fernando de Castro, por las que se le entregaron 450 reales y medio. Son pocas las noticias que se han conservado sobre su trayectoria, del que sabemos que trabajó en la reparación de unas casas del Duque de Alcalá en la collación de San Lorenzo, junto con el albañil Francisco de Vera y los carpinteros Francisco de Torres y Pedro Chaves (Arenillas Torrejón, 2005: 232). También se le ha documentado como fiador, en 1656 (Kinkead, 2009: 435), del aprendiz de pintor Antonio de Lejalde, que estuvo bajo la tutela del maestro pintor Alonso Pérez.

\section{Juan Afanador y Manuel García: La construcción de una nueva armadura para la antigua ropería}

En el último tercio del siglo XVII, trabajaron para Santa Inés el albañil Juan Afanador, y el carpintero Manuel García ${ }^{11}$, artífices cuya labor se centró en el reconocimiento de viviendas e intervenciones del edificio monástico. Ambos artistas fueron compañeros en otras ocasiones, como en 1692 (Cruz Isidoro, 1993: 118), cuando conjuntamente con Pedro Romero, Juan Durán y José García fueron llamados para el reconocimiento del estado de ruina en el que se encontraba la casa profesa de los jesuitas de la Anunciación. Posteriormente, en el año de 1700 (Sancho Corbacho, 1993: 111), Juan Afanador trabajó como maestro de obras y alcalde alarife de Sevilla, junto con Fray Manuel Ramos y Leonardo de Figueroa en el Hospital de la Misericordia (Bonet Correa, 1978: 124). Familiarmente se le ha venido relacionando con Pedro Luis Afanador (Pemán Medina, 1977: 100), maestro alarife nacido en Sevilla que trabajaría en el Hospital de las Mujeres de Cádiz.

\footnotetext{
${ }^{10}$ A.H.P.S: Sección Protocolos Notariales. Oficio 11, Leg. 6998. Año de 1644. Escribano público Rodrigo de Abreu. Fol. 39.

${ }^{11}$ A.S.I: Leg, 32.
} 
La primera intervención de ambos en Santa Inés data del 23 de diciembre $1687^{12}$, cuando acordaron ante sus fiadores Diego Salmerón, maestro de albañilería, y el carpintero Juan Romero, ante el escribano público Gabriel Fernando de Ortega, realizar la nueva armadura de la antigua ropería por 9.000 reales de vellón, obra que debía que ejecutarse en tres meses tras la fecha del contrato ${ }^{13}$. El 1 de enero de $1688^{14}$, otorgaron carta de pago a la congregación de 4.500 reales, pertenecientes a los 9.000 acordados para la obra. Para su ejecución, la Madre Abadesa Sor María Josefa Valdés solicitó licencia de obra a Joan Romero, lector jubilado y ministro provincial de los franciscanos y monjas de Santa Clara, quien dio su visto bueno el 15 de octubre de $1687^{15}$. En dicho año ${ }^{16}$, ambos maestros emprendieron unas obras de rehabilitación en los corrales y lavaderos de la comunidad ${ }^{17}$, con un coste de 3.343 reales de vellón y 16 maravedíes, cantidad que les fue entregada el 19 de enero de $1688^{18}$.

Años más tarde, en $1692^{19}$, Juan Afanador trabajó individualmente para Santa Inés en el reparo de unos tejados, obra ejecutada por 937 reales y 20 maravedíes. El 20 de abril de 1693, recibió 1.600 reales de vellón por una obra en el compás, cuyas labores se desconocen ${ }^{20}$, obra por la que se sacaron 2.000 reales de vellón del arca de principales. Un año más tarde, mientras disfrutaba del título de maestro de obras de albañilería de la Casa Hospital de la Misericordia, asistió al reconocimiento de una casa y un pilar del cortijo del Mazarrón en Paterna del Campo, tasando la casa en 1.654 reales y el citado pilar, que debía construirse de nuevo, en 260 reales $^{21}$. De forma colateral a su labor en Santa Inés, trabajó en las casas que disfrutaba Don Francisco Matamoros de Loyola, mayordomo del convento, en la collación de San Pedro en 1687, intervención por la que recibió 123 reales y medio ${ }^{22}$.

\footnotetext{
${ }^{12}$ A.H.P.S: Sección Protocolos Notariales. Oficio 11, Leg 7072. Escribano público Gabriel Fernando. Fols 1353-1355.

${ }^{13}$ A.H.P.S: Sección Protocolos Notariales. Oficio 11, Leg 7072. Escribano público Gabriel Fernando. Fol. 1354.

A.H.P.S: Sección Protocolos Notariales. Oficio 11, Leg 7073. Escribano público Gabriel Fernando. Fol. 585.

${ }^{14}$ A.H.P.S: Sección Protocolos Notariales. Oficio 11, Leg 7073. Escribano público Gabriel Fernando. Fol. 1. A.S.I: Legajo 40, Libro de entrada y salida del arca desde el año de 1674 hasta el de 1717. Fol. 20.

${ }^{15}$ A.H.P.S: Sección Protocolos Notariales. Oficio 11, Leg 7072. Escribano público Gabriel Fernando. Fol. 1355.

${ }^{16}$ A.H.P.S: Sección Protocolos Notariales. Oficio 11, Leg 7073. Escribano público Gabriel Fernando. Fol. 84-91.

${ }^{17}$ A.H.P.S: Sección Protocolos Notariales. Oficio 11, Leg 7073. Escribano público Gabriel Fernando. Fol. 92.

${ }^{18}$ A.H.P.S: Sección Protocolos Notariales. Oficio 11, Leg 7073. Escribano público Gabriel Fernando. Fol. 563.

${ }^{19}$ A.H.P.S: Sección Protocolos Notariales. Oficio 11, Leg 7076 .Escribano público Gabriel Fernando. Fol. 1218.

${ }^{20}$ A.S.I: Legajo 40, Libro de entrada y salida del arca desde el año de 1674 hasta el de 1717. Fol. 8 v.

${ }^{21}$ A.H.P.S: Sección Protocolos Notariales. Oficio 20, Leg 14.064. Escribano público Jacinto de Medina. Fol. 215.

${ }^{22}$ A.H.P.S: Sección Protocolos Notariales. Oficio 20, Leg 14.067. Escribano púbico Jacinto de Medina. Fol. 938.
} 


\section{Pedro Romero como supervisor de obras en propiedades de Santa Inés}

En $1695^{23}$ hizo acto de presencia el albañil y alcalde alarife Pedro Romero en unas propiedades particulares de Santa Inés ${ }^{24}$. Son pocas las noticias conservadas sobre este primer eslabón de una saga de maestros de albañilería. El inicio de su actividad profesional se ha documentado en 1675 (Falcón Márquez, 2011: 227), al incorporarse junto con Esteban García a las obras de la Colegial del Salvador. Gracias al hallazgo de dos documentos, lo situamos en la obra de la Capilla de las Benditas Ánimas del Purgatorio del Hospital de San Onofre del convento Casa Grande de San Francisco ${ }^{25}$ en 1672, dato que nos permite adelantar la fecha de su carrera profesional.

Su actividad en Santa Inés se centró en la supervisión de los presupuestos de obras otorgados por el maestro albañil Miguel Baptista, artífice que trabajó para este monasterio entre los años de 1693 y 1694. Su primera intervención se documenta en la casa ${ }^{\circ} 1$ de la calle Alcaicería de la Seda, en la que se gastaron 626 reales y medio en diferentes obras de reparos ${ }^{26}$. Al parecer Baptista dio carta de pago a las religiosas de 390 reales, relación de gastos que no respondían al aprecio de Pedro Romero, quien tasó su trabajo en 236reales.

El siguiente trabajo documentado, son unas obras de mejora en cinco casas del barrio del Duque en la que se destinaron 354 reales $^{27}$. De nuevo Pedro Romero corrigió el presupuesto de Miguel Baptista, tasando las obras en 100 reales. Posteriormente Miguel Baptista trabajó en una nueva pared de la casa $n^{\circ} 31$ de la calle del Pepino, con un valor de 350 reales y medio. Se deja constancia en el registro de pago que la obra no fue apreciada por Pedro Romero, por lo que se reservó el derecho de reclamación de dicho gasto.

También intervino en unas casas situadas en las Pasaderas ${ }^{28}$, en las que entregó dos cartas de pago, una de 329 reales y medio y otra de 1.434 reales. De nuevo, Miguel Baptista no contó con el beneplácito de Pedro Romero, quien estimó las obras en 1.180 reales. En la collación de Santa María la Blanca, trabajó en la propiedad no 45 de la calle que iba desde Santa María la Blanca a San Bartolomé, en la que gastaron 407 reales y medio, la cual reparó por segunda vez, con un coste de

\footnotetext{
${ }^{23}$ A.S.I: Leg, 32. Libro 1, año de 1695. Cuentas de mayordomía finales del tiempo que lo fue Don Francisco Martínez de Alba. Fol. 33.

${ }^{24}$ A.H.P.S: Sección Protocolos Notariales. Oficio 17, Leg 11.118. Escribano Público Francisco Fernández Cano. Fols 835,912 y 1505 .

${ }^{25}$ A.H.P.S: Sección Protocolos Notariales. Oficio 17, leg .11807. Escribano Francisco Fernández Cano. Fol. 228 y 459.

${ }^{26}$ A.S.I: Legajo 32, Libro 1, año de 1695. Cuentas de mayordomía finales del tiempo que lo fue Don Francisco Martínez de Alba. Fol. 35

27 A.S.I: Legajo 32, Libro 1, año de 1695. Cuentas de mayordomía finales del tiempo que lo fue Don Francisco Martínez de Alba. Fol. 35 r y 36.

${ }^{28}$ Ibidem, Fol. 37.
} 
232 reales y medio, lo que resultaba un gasto total de 640 reales y medio. En esta ocasión Pedro Romero tras su visita, pudo comprobar que no se había realizado la reparación ordenada por Don Francisco Martínez de Alba, mayordomo de Santa Inés, por lo que se vio obligado a dar por excluida la declaración jurada por Miguel Baptista ${ }^{29}$.

La última supervisión de Pedro Romero se efectuó sobre unas casas, cuya ubicación desconocemos, por 300 reales $^{30}$. La actividad de Miguel Baptista continuó hasta 1694 en trabajando la casa $n^{\circ} 64$ de la calle Costales, collación de San Gil ${ }^{31}$.

\section{Conclusiones}

Como conclusión destacaremos la importancia de los trabajos de conservación, mejoras y mantenimiento del conjunto arquitectónico, y de sus propiedades, como una constante durante la centuria del XVII en el convento de Santa Inés. Dichas intervenciones, que fueron ejecutadas por un importante conjunto de maestros de alarifes que dejaron plasmada su impronta en determinadas obras menores, forman parte, y a la vez complementan, la historia del edificio monástico, aportando nuevos datos que permiten acrecentar la actividad de estos artífices que disfrutaron del cargo de maestro de obras del cenobio, puesto que compaginaron con otros cargos en otras instituciones sevillanas.

\section{Referencias bibliográficas}

AA.VV (1990). Intervenciones en el patrimonio arquitectónico: 1980-1985. Ministerio de Cultura, Instituto de Conservación y Restauración de Bienes Culturales, Madrid.

ARENILLA TORREJÓN, Juan Antonio (1992) "Nuevos datos sobre el arquitecto Diego López Bueno", Boletín del Seminario de Estudios de Arte y Arqueología. Tomo 58, pp. 385-392.

ARENILLAS TORREJÓN, Juan Antonio (2005). Del Clasicismo al Barroco: Arquitectura sevillana del siglo XVII. Diputación Provincial de Sevilla, Sevilla.

BALLESTEROS BERETTA, Antonio (1913), Sevilla en el siglo XIII. Madrid.

\footnotetext{
${ }^{29}$ Ibid Fols 37-38.

${ }^{30}$ Ibid Fol. 38.

${ }^{31}$ A.S.I: Leg. 32, libro 1 mayordomía Francisco Martínez de Alba. Fol 178.
} 
BONET CORREA, Antonio (1973). Andalucía Barroca (Arquitectura y urbanismo). Ediciones Polígrafa: Barcelona.

BOSARTE, Isidoro (1804).Viaje artístico a varios pueblos de España, Vol.1. Imprenta Real, Madrid.

CÓMEZ RAMOS, Rafael (2006) Los constructores de la España medieval. Universidad de Sevilla, Sevilla.

CRUZ ISIDORO, Fernando (1993) “José García, maestro mayor del Consejo Hispalense”, Laboratorio de Arte, № 6, pp. 103-127.

CRUZ ISIDORO, Fernando (1995) "Sobre el arquitecto Juan de Segarra, teniente de maestro mayor del Consejo Hispalense", Laboratorio de Arte, nº 8, pp. 417-429.

DE LA BANDA VARGAS, Antonio (2007). Las cinco llagas. De Hospital a Parlamento de Andalucía. Centro de Publicaciones del Parlamento de Andalucía, Sevilla.

FALCÓN MÁRQUEZ, Teodoro (2011). "Pedro Romero (1638-1711) Arquitecto del barroco sevillano", Laboratorio de Arte, no 23, pp. 225-251.

GESTOSO PÉREZ, José (1889). Sevilla monumental y artística: Historia y descripción de todos los edificios notables, religiosos y civiles, que existen actualmente en esta ciudad, y noticia de las preciosidades artísticas y arqueológicas que en ellos se conservan. Vol. I. Sevilla.

GESTOSO PÉREZ, José (2001): Ensayo de un diccionario de los artífices que florecieron en Sevilla desde el siglo XIII al XVIII inclusive. Anacleta, Pamplona.

GÓMEZ LÓPEZ, Consuelo (1991). "Los Alarifes en los oficios de la construcción (Siglos XVXVIII)”, Espacio, Tiempo y Forma, Serie Vil, Historia del Arte, t. 4, 1991, pp. 39-52 GONZÁLEZ DE CALDAS, Victoria (2000) “¿Judios o cristianos?: El proceso de fe “Sancta Inquisitio",". Universidad de Sevilla, Sevilla.

GONZÁLEZ DE CALDAS, Victoria (2008). El poder y su imagen. La Inquisición real. Universidad de Sevilla, Sevilla.

GONZÁLEZ DE LEÓN, Félix (1844). Noticia artística, Histórica y curiosa de todos los edificios de Sevilla, Sevilla.

GUERRERO LOVILLO, José (1995). “Los maestros yeseros del siglo XVI”, Archivo español de arte, Tomo 28, pp. 39-53. 
KINKEAD, Duncan (2009). Pintores y Doradores en Sevilla: 1650-1699. AuthorHouse: EE.UU.

LEDESMA GAMEZ, Francisco (1996). "Noticias sobra Diego de Mendoza, entallador y carpintero en Osuna (1576-1617)”, Laboratorio de Arte n 9, pp. 105-124.

LEDESMA GÁMEZ, Francisco y MARTÍN VÁQUEZ, Antonio (2012) “Un ejemplo de la tradición mudéjar en Osuna. La armadura para cubrir de la capilla mayor del convento de la Concepción”, Cuadernos de los amigos de los museos de Osuna, № 14, pp. 63-67.

MARÍN FIDALGO, Ana María (1990). El Alcázar de Sevilla bajo los Austrias. Vol. II. Guadalquivir, Sevilla.

MARÍN FIDALGO, Ana María (1991) “Más datos sobre el colegio de San Hermenegildo de Sevilla”, Archivo hispalense: Revista histórica, literaria y artística. Tomo 91, № 276-278, pp. 303325

MARÍN FIDALGO, Ana María (1991) "Pintura de corte humanista en los jardines del Alcázar de Sevilla: las decoraciones de los cenadores Ochavado y del León”, Archivo español de arte, Tomo 64, no 253, pp. 213-218.

MARÍN FIDALGO, Ana María (2006): El Real Alcázar de Sevilla bajo los Borbones: El reinado de Felipe V(1700-1746). Guadalquivir, Sevilla.

MORÓN DE CASTRO, María Fernanda (1995). La iglesia de San Miguel. Cinco siglos en la historia de Morón (XIV-XVIII). Universidad de Sevilla, Sevilla.

PEMÁN MEDINA, María (1977). “Contribución al estudio de la arquitectura gaditana: El maestro Afanador", Archivo español de arte, Tomo 50, N 198, pp. 97-120.

QUILES GARCÍA, Fernando (1990). "Introducción al estudio de la yesería barroca" en Pedro de Mena y su época, pp. 565-575. Junta de Andalucía, Málaga.

SANCHO CORBACHO, Antonio (1993). Documentos para la historia del Arte en Andalucía (VIVII). Laboratorio de Arte, Sevilla.

SANCHO CORBACHO, Heliodoro (1928): Documentos para la Historia del Arte en Andalucía. Tomo II. Laboratorio de Arte, Sevilla.

SANCHO CORBACHO, Heliodoro (1930). Contribución documental al estudio del arte sevillano. Universidad de Sevilla, Sevilla. 
TOAJAS ROGER, Ángeles. (1984). "Los oficios de alarifes en el siglo XVII”, III Simposio Internacional de mudejarismo. Diputación de Teruel, Teruel, pp. 163-172.

VALDIVIESO GONZÁLEZ, Enrique y SERRERA CONTRERAS, Juan Miguel (1985): Historia de la pintura española: escuela sevillana del primer tercio del siglo XVII. Centro de Estudios Históricos, Departamento de Historia del Arte Diego Velázquez, Madrid. 